\title{
STUDI PENGEMBANGAN FASILITAS WISMA ATLIT
}

\author{
Azis Alimuddin ${ }^{1}$ \\ ${ }^{1}$ Prodi Arsitektur, Fakultas Teknik, Universitas Muslim Indonesia
}

\begin{abstract}
Abstrak
Makassar merupakan salah satu kota terbesar di Indonesia, saat ini telah mengalami perkembangan pesat dalam bidang olahraga. Hal ini ditunjang dengan semakin banyak event olahraga yang di selenggarakan di Makassar. Fasilitas pendukung olahraga pun cukup banyak dan berkembang seperti gelanggang olahraga, stadion sepak bola, serta fasilitas lain seperti kolam renang dan sebagainya. Oleh karena itu, dengan adanya Wisma Atlet ini bisa menjadi wadah untuk meningkatkan potensi anak bangsa di dunia olahraga, khususnya di kota Makassar. Karena jika dilihat dari segi kemampuan, atlet di kota Makassar sangat banyak yang bisa dan mampu bersaing di kanca internasional. Itu semua sebagai motivasi buat mereka yang ingin mengembangkan keahliannya dalam bidang olah raga. Diharapkan dengan adanya Wisma Atlet ini, para atlet-atlet yang berkunjung ke Makassar dapat beristirahat dengan nyaman dengan fasilitas yang lengkap yang telah di sediakan. Atlet-atlet ini juga disuguhkan dengan panorama kota Makassar yang tidak akan di jumpai di kota-kota lain di Indonesia.
\end{abstract}

Kata kunci: Pengembangan, Wisma, Atlit

\section{PENDAHUUAN}

Makassar merupakan salah satu kota terbesar di Indonesia, saat ini telah mengalami perkembangan pesat dalam bidang olahraga. Hal ini ditunjang dengan semakin banyak event olahraga yang di selenggarakan di Makassar. Fasilitas pendukung olahraga pun cukup banyak dan berkembang seperti gelanggang olahraga, stadion sepak bola, serta fasilitas lain seperti kolam renang dan sebagainya. Wisma atlet terpilih menjadi fokus pembahasan skripsi ini karena sampai saat ini juga Kota Makassar belum mempunyai fasilitas wisma atlet yang merupakan salah satu sarana pendukung penting untuk kegiatan olahraga sebagai tempat peristirahatan atlet melepas lelah.

Perkembangan jumlah atlet yang dibina langsung oleh pengurus Komite Olahraga Nasional Indonesia (KONI) Sulawesi Selatan meningkat 30\% setiap tahunnya untuk semua jenis cabang olahraga, tercatat dari tahun 2011-2014. Saat ini sudah mencapai 150 atlet dari berbagai macam jenis olah raga, yaitu tahun 2011 sebanyak 70 atlet, tahun 2012 sebanyak 95 atlet, tahun 2013 sebanyak 132 atlet, dan sekarang tahun 2014 sebanyak 150 atlet, yang direkrut dari tingkat prestasinya masing-masing, berkembang sekitar $30 \%$ setiap tahunnya. Dengan perkembangan yang pesat saat ini, seharusnya Makassar mampu bersaing dengan kota-kota besar yang ada di Indonesia, dan harapan kedepannya juga mampu untuk go internasional. (KONI Provinsi Sulawesi Selatan, 2011-2014).

Oleh karena itu, dengan adanya Wisma Atlet ini bisa menjadi wadah untuk meningkatkan potensi anak bangsa di dunia olahraga, khususnya di kota Makassar. Karena jika dilihat dari segi kemampuan, atlet di kota Makassar sangat banyak yang bisa dan mampu bersaing di kanca internasional.

Diharapkan dengan adanya Wisma Atlet ini, para atlet-atlet yang berkunjung ke Makassar dapat beristirahat dengan nyaman dengan fasilitas yang lengkap yang telah di sediakan. Atlet-atlet ini juga disuguhkan dengan panorama kota Makassar yang tidak akan di jumpai di kota-kota lain di Indonesia. Langkah kita untuk menyatukan kondisi ideal yang ada saat ini di kota Makassar kemudian berusaha untuk menjadikan kondisi ideal tersebut menjadi kenyataan, kiranya kota Makassar kedepan dapat mewujudkan impian masyarakat dengan membuat suatu wadah yang mampu menampung atlet-atlet muda dan berbakat, serta mendatangkan atlet-atlet baru dengan berbagai macam keahlian dibidangnya yang dapat mengharumkan bangsa Indonesia khususnya kota Makassar.

\section{ISI PENELITIAN}

\section{1 Metode Penelitian}

Lokasi penelitian berada di kelurahan Barombong, kecamatan Tamalate, kota Makassar, Sulawesi Selatan. Tepatnya berada di kawasan Olahraga terpadu dan memilki luas site $\pm 42.750 \mathrm{~m}^{2}$. Metode yang digunakan adalah Bagaimana konsep perencanaan Wisma Atlit yang layak sebagai tempat yang dapat menampung kegiatan keolahragaan agar lebih efektif dan efisien.

\section{2 Hasil}

2.2.1 Pengolahan Site

a. Kondisi fisik site

Site berada di kelurahan Barombong, kecamatan Tamalate, kota Makassar, Sulawesi Selatan. Tepatnya berada di kawasan Olahraga terpadu dan memilki luas site $\pm 42.750 \mathrm{~m}^{2}$. 


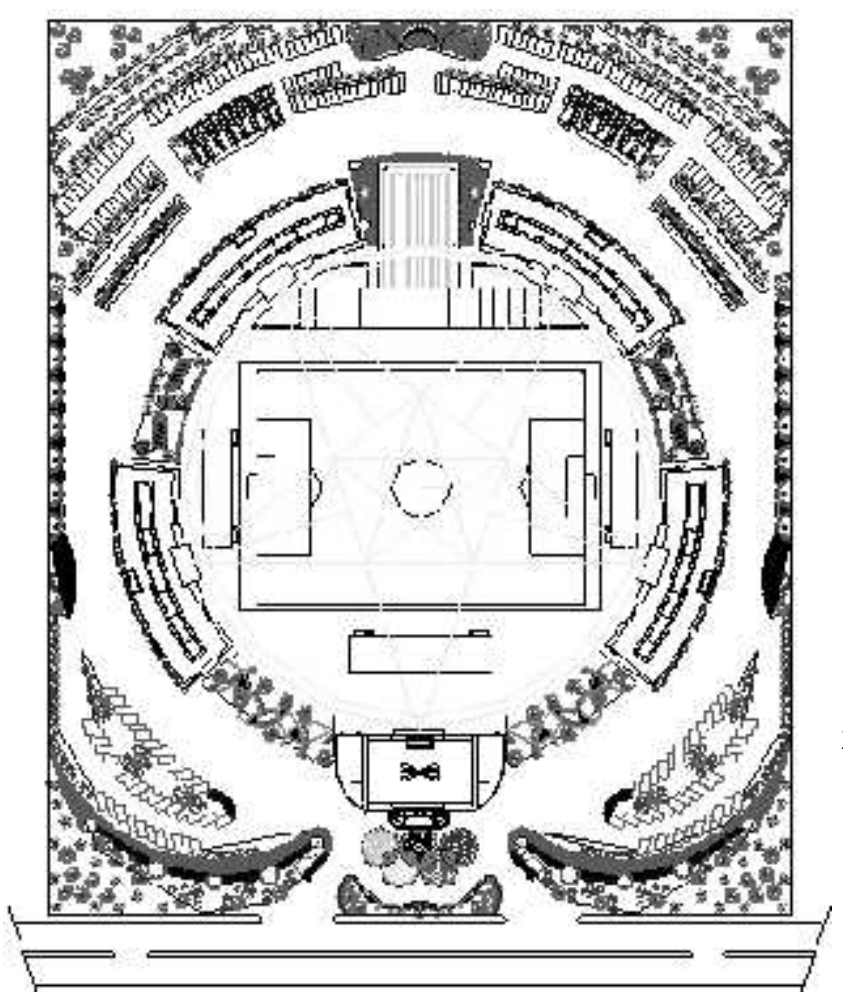

Gambar 1 : Bentuk Siteplan Wisma Atlet di Makassar

Sumber : Penulis, 2016

b. Pencapaian

Pencapaian ke site akan sangat mudah karena site berada tepat di depan jalan poros Metro Tanjung Bunga. Dapat diakses juga dari Kabupaten Takalar dengan melalui jalan Barombong menuju Jalan mappainga dengan menggunakan kendaraan pribadi maupun kendaraan umum.

c. Sirkulasi

Kegiatan yang saling berhubungan dan saling menunjang tetapi dapat berdiri sendiri, maka pola sirkulasi yang dipilih adalah lintasan umpan balik. Hubungan Ruang dengan Sirkulasi Karena gedung ini memiliki zona kegiatan yang saling mendukung dan melengkapi, maka pola sirkulasi yang dipilih adalah sirkulasi melewati ruang, menembus ruang dan berakhir dalam satu ruang. Pola sirkulasi yang ada diarahkan seperti menerus, jelas, dan terarah, memberikan keleluasaan pengamatan obyek serta sirkulasi yang tidak membosankan.

d. View

Menampilakn view bangunan edukatifkomersial yang menuntut ekspose bangunan yang optimal. View yang optimal ialah berorientasi ke Barat dimana view bangunan menghadap langsung ke jalan raya.

e. Orientasi Matahari

1) Penerangan alami dalam ruang dengan mengoptimalkan sinar matahari. Yaitu pada ruang tidur/kamar, dapur/ruang makan, fasilitas kantor, perpustakaan dan ruang latihan fisik.

2) Untuk mengurangi panas dalam bangunan dikarenakan bangunan tepat berada pada arah gerak matahari yaitu pada bagian barat dan timur gedung maka didesain dengan peletakan vegetasi pada kedua bagian tersebut untuk mengurangi sinar matahari berlebih.

f. Kebisingan

Untuk meminimalisir kabisingan yang ada pada kawasan Olahraga terpau ini maka diperlukan meletakkan vegetasi disekitar tapak yang langsung berhubugan dengan sumber bising, diharapkan dapat memfilter suara bising dari jalan raya.

\subsubsection{Tata Ruang Luar}

a. Soft Material

Jenis tanaman yang digunakan tergantung fungsi dan penempatannya.

1) Pada area parkir mobil dan motor dipergunakan pohon Trembesi dan Mahoni sebagai peneduh dan akustik alami.

2) Pada taman tepi jalan utama dipergunakan pohon Palm Raja, dan bunga Kana sebagai pengarah jalan.

3) Tanaman penutup tanah (ground cover), atau pada sculpture park yang dipergunakan ialah rumput peking atau rumput manila.

b. Hard Material

1) Lampu taman, jenis lampu yang digunakan adalah lampu protosel yang secara otomatis menyala jika suasana mendung atau gelap.

2) Lampu jalan, digunakan lampu merkuri.

3) Paving block dipasang pada jalur pedestrian dan tempat latihan outdoor.

\subsubsection{Tata Ruang Mikro}

a. Besaran Ruang

1) Ruang Akomodasi $=1.249,34 \mathrm{~m}^{2}$

2) Ruang Pengelolah dan Atlet =

3) Ruang Security and service $=347,82 \mathrm{~m}^{2}$

4) Ruang Driving Range (latihan) $=\quad 899,94 \mathrm{~m}^{2}$

5) Ruang instalasi Pemeliharaan sarana $=423,19 \mathrm{~m}^{2}$ Jumlah+40\% sirkulasi $\mathbf{m}^{2}$

$$
=\quad 5.689,43 \mathrm{~m}^{2}
$$


b. Fasiitas Luar Bangunan

1) Area Parkiran

\begin{tabular}{|c|c|c|}
\hline $\begin{array}{l}\text { Motor } \\
\text { Area Parkir }\end{array}$ & $=$ & $506,25 \mathrm{~m}^{2}$ \\
\hline Bus & $=$ & $395,83 \mathrm{~m}^{2}$ \\
\hline Area Parkiran & & \\
\hline $\begin{array}{l}\text { Mobil } \\
\text { Kolam }\end{array}$ & $=$ & $2.783 \mathrm{~m}^{2}$ \\
\hline $\begin{array}{l}\text { Renang } \\
\text { Lapangan }\end{array}$ & $=$ & $1.250 \mathrm{~m}^{2}$ \\
\hline Sepak Bola & $=$ & $8.084,89 \mathrm{~m}^{2}$ \\
\hline Jumlah & & $3.019,99 \mathrm{~m}^{2}$ \\
\hline
\end{tabular}

Jadi kebutuhan total luas bangunan :

Luas bangunan

\begin{tabular}{|c|c|c|}
\hline Wisma Atlet & $=$ & $5.689,43 \mathrm{~m}^{2}$ \\
\hline Luas parkir & $=$ & $3.685,1 \mathrm{~m}^{2}$ \\
\hline $\begin{array}{l}\text { Luas kolam } \\
\text { renang }\end{array}$ & $=$ & 1.250 \\
\hline $\begin{array}{l}\text { Luas lapangan } \\
\text { sepak bola }\end{array}$ & $=$ & $8.084,89 \mathrm{~m}^{2}$ \\
\hline Luas total & $=$ & $8.709,42 \mathrm{~m}^{2}$ \\
\hline
\end{tabular}

Jadi total keseluruhan luasan site pada bangunan Wisma Atlet adalah 18.709,42 $\mathbf{~ m}^{2}$. Building Covering (BC) : Open Space $(\mathrm{OS})=$ 40:60

$\mathrm{BC}=$ bangunan berlantai 4

$=$ total - lahan parkir

$=18.709,42 \mathrm{~m}^{2}-3.685,1 \mathrm{~m}^{2}$

$\mathrm{BC}=15.024,32 \mathrm{~m}^{2}$

$=\mathrm{BC} / 4$ lantai $=15.024,32 / 4$

$=2.504,05$

$\mathrm{OS}=\frac{\mathrm{BC} \times 60 \%}{40 \%}$

$=\frac{15.024,32 \mathrm{~m}^{2} \times 60 \%}{40 \%}$

$=\underline{9.014,592}$

$$
40 \%
$$

$=22.536,48 \mathrm{~m}^{2}$

Building Covering (BC) : Open Space (OS)

$$
=40: 60
$$$$
=15.024,32 \mathrm{~m}^{2}(40 \%): 22.536,48 \mathrm{~m}^{2}
$$$$
(60 \%)
$$

Luasan tapak $=\mathrm{BC}+\mathrm{OS}+$ parkir

$$
\begin{aligned}
& =15.024,32 \mathrm{~m}^{2}+22.536,48 \mathrm{~m}^{2}+ \\
& 3.685,1 \mathrm{~m}^{2}=\mathbf{4 1 . 2 4 4 , 9} \mathbf{m}^{2}
\end{aligned}
$$

Jadi, total luasan gedung Wisma Atlet adalah $\underline{\mathbf{4 1 . 2 4 4 , 9 \mathrm { m } ^ { 2 }}}$

\subsubsection{Bentuk dan Penampilan Bangunan}

Bentuk dan penampilan bangunan Wisma Atlet di Makassar didesain Bentuk tampilan bangunan tidak lepas dari pertimbangan fungsi utama Wisma Atlet sebagai bangunan edukatif-komersial, sebagai pusat kegiatan yang berhubungan dengan olahraga.Pada tampilan bangunan kesesuaian dengan karakteristik bangunan Wisma Atlet dengan pendekatan desain yang ekspresif yang merupakan penggabungan ekspresi bentuk dan kebebasan ide (gagasan yang mengalir) baik pada bangunan maupun sistem yang digunakan di dalamnya. Mencerminkan sebuah bangunan Wisma Atlet sebagai bangunan edukatif- komersial yang atraktif, rekreatif, terbuka dan komunikatif, yang merupakan perwujudan karakter kegiatan yang diwadahinya sehingga mampu menjadi salah satu daya tarik bagi para atlet dan pengunjung untuk melihat kegiatan yang berlangsung didalamnya.

\subsubsection{Tata Ruang Dalam}

Pemilihan bahan, pola lantai dan elemenelemen interior lainnya merupakan pertimbangan dalam menentukan kenyamanan sebuah ruang serta kesesuaian dengan karakteristik kegiatan sehingga diharapkan tampilan interior mampu mendukung kegiatan yang terjadi dalam Wisma Atlet. Kantor

a. Kantor

Kantor adalah sarana penunjang utama bagi seseorang untuk melakukan pekerjaannya. Desain interior dengan suasana lebih fokus dan terkonsentrasi namun tetap bersifat santai. Desain ruang kantor yang direncanakan yaitu desain yang bersifat santai dan bersih. Kantor tampak terlihat rapi dengan balutan dominan warna cokelat pada pembatas ruangan dan warna putih pada plafonnya. Ruangan kantor dibangun dengan rapi dari sisi sekat dinding kayu yang dilapisi dengan HPL dan sedikit campuran walpaper sehingga terkesan lebih nyaman. Meja kantor juga diserasikan warnanya dengan warna yang sama seperti pada tembok dan dinding pembatas.

b. Ruang Fitnes

Desain tampilan maksimum desain ruang fitness adalah melakukan pengaturan tata letak peralatan gym dengan benar. Ada banyak peralatan gym yang bisa kita dapatkan. Memilih peralatan dengan kualitas terbaik yang sesuai dengan anggaran dan sesuai dengan apa yang kita butuhkan. Ketika melakukan pengaturan ruang, gunakan sudut-sudut ruangan atau di dekat dinding untuk alat-alat yang berat dan peralatan kecil di tengah ruangan

c. Kolam Renang

Ukuran kolam renang standar nasional: Panjang kolam adalah $50 \mathrm{~m}$, lebar kolam renang adalah $25 \mathrm{~m}$. Kedalaman kolam minimum adalah $2 \mathrm{~m}$. Garis lebar: 2,5 m, lintasan: 8, suhu air pada kolam renang: $25^{\circ} \mathrm{C}-28^{\circ} \mathrm{C}$. Jika dilakukan pada malam hari pencahayaannya adalah 1500 lumen.

\subsubsection{Kondisi fisik bangunan}

\section{a. Sistem Struktur dan Material}

1.) Struktur bangunan

- Sub struktur 
Modul struktur yang dipakai adalah jarak/ kolom tidak beraturan

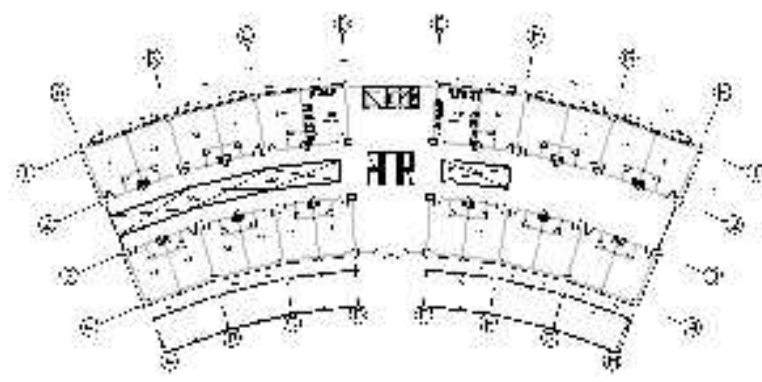

Gambar 2 : Modul Kolom pada Struktur Wisma Atlet

Sumber : Penulis, 2016

Struktur utama memakai pondasi pancang dan poer plat, sebagai penyalur beban dari atas atap yaitu dimana pondasi ini siap memikul beban dari atap yang langsung disalurkan ke kolom dan kedalam tanah.

- Super struktur

Lantai

Material lantai yang digunakan adalah tegel keramik untuk ruangan-ruangan area umum terutama area lobby/hall.

Dinding

Struktur dinding menggunakan pasangan batu bata.

- Upper Struktur

Upper struktur Wisma Atlet adalah rangka kayu, rangka baja ringan dan pelat Beton.

\section{b. Sistem Perlengkapan Bangunan}

1) Sistem pencahayan

Sistem pencahayaan yang digunakan pada Wisma Atlet Di Makassar ada dua yaitu :

- Pencahayaan alami

Pencahayaan alami digunakan sedapat mungkin pada siang hari pada ruang tidur/kamar, dapur/ruang makan, fasilitas kantor dan ruang latihan fisik.

- Pencahayaan Buatan

Pencahayaan buatan digunakan pada malam hari dan ruang-ruang tertutup pada siang hari. (http:/pencahayaanalamidanbuatan.co.id/2014, di akses 09 Januari 2015)

2) Sistem Penghawaan

Sistem Penghawaan yang digunakan pada Wisma Atlet Di Makassar ada dua yaitu :

a) Penghawaan alami

Merupakan sistem penghawaan dalam kondisi normal bagi pemakai ruangan dengan memanfaatkan kecepatan arah angin, kelembaban dan lingkungan di sekitar site dengan cara penggunaan jendela dan ventilasi.

b) Penghawaan buatan

Merupakan sistem penghawaan yang menggunakan AC split, exhaust fan dan blower. (http:/penghawaanalamidanbuatan.co.id/2014, di akses 09 Januari 2015)

3) Sistem Air bersih

Sumber utama air bersih berasal dari PDAM dan sumur pompa (deep well) sebagai cadangan. Air ditampung pada reservoir kemudian didistribusikan ke ruang-ruang yang membutuhkan.

4) Sistem pembuangan air kotor Untuk pembuangan air kotor yang bersifat padat dari lavatory, disalurkan ke septictank dan peresapan sedangkan untuk pembuangan air kotor cair diusahakan melalui saluran tertutup menuju drainase kota.

5) Jaringan listrik

Sumber daya listrik pada bangunan ini berasal dari Perusahaan Listrik Negara (PLN) yang didistribusikan keseluruh bangunan. Sebagai cadangan dipakai sumber tenaga dari genset yang ditempatkan pada ruang genset. Genset akan bekerja secara otomatis apabila listrik padam dalam waktu 5 detik.

6) Sistem Pembuangan Sampah

Sistem Pembungan Sampah dilakukan dengan :

a. Menyediakan tempat-tempat sampah pada ruang tertentu yang kemungkinan menghasilkan sampah yang cukup banyak.

b. Membuat bak penampungan atau tong sampah agar dinas kebersihan kota mudah mengangkut sampah ketempat pembuangan akhir.

7) Sistem sirkulasi

Sistem sirkulasi pada dasarnya terbagi 2 yaitu sirkulasi vertikal dan horisontal, berdasarkan dari hasil analisis pada bab sebelumnya, maka dipilih sistem sirkulasi sebagai berikut:

a. Sirkulasi horisontal

Pola sirkulasi yang digunakan adalah pola sirkulasi 1 arah dan dua arah,

b. Sirkulasi vertikal

Menggunakan lift dan Tangga.

(Sumber : Http://www.google.com, modifikasi 2015)

8) Sistem keamanan bangunan

a. Penanggulangan bahaya kebakaran

Penanggulangan dilakukan dengan menyediakan fasilitas-fasilitas pencegah dan pemadam kebakaran, seperti smoke detector, springkler, hydrant box, dan hydrant portable. Wisma Atlit Makassar ini mengunakan sistem pencegahan bahaya kebakaran jenis Fire Hydrant central dengan sistem jalur pemipaan pada plafon ruangan dan juga Fire Hydrant digunakan diluar gedung. Selain menggunkan Fire Hydrant Center, di dalam gedung juga menggunakan hydrant yang diletakan disetiap ruang sebagai antisipasi. Sementara untuk menanggulangi jika terjadi kebakaran dilakukan dengan memangil petugas pemadam kebakaran melalui alat komunikasi telepon.

b. Antisipasi terhadap bahaya petir 
Sistem pengamanan terhadap bahaya petir digunakan peralatan dengan system tongkat Faraday dengan pertimbangan cukup efisien dan merupakan pengembangan system tongkat Franklin.

(Sumber : Http://www.google.com, modifikasi 2015)

\section{KESIMPULAN}

Pencapaian ke site akan sangat mudah karena site berada tepat di depan jalan poros Metro Tanjung Bunga. Dapat diakses juga dari Kabupaten Takalar dengan melalui jalan Barombong menuju Jalan mappainga dengan menggunakan kendaraan pribadi maupun kendaraan umum.

Kegiatan yang saling berhubungan dan saling menunjang tetapi dapat berdiri sendiri, maka pola sirkulasi yang dipilih adalah lintasan umpan balik. Hubungan Ruang dengan Sirkulasi Karena gedung ini memiliki zona kegiatan yang saling mendukung dan melengkapi, maka pola sirkulasi yang dipilih adalah sirkulasi melewati ruang, menembus ruang dan berakhir dalam satu ruang. Pola sirkulasi yang ada diarahkan seperti menerus, jelas, dan terarah, memberikan keleluasaan pengamatan obyek serta sirkulasi yang tidak membosankan.

Menampilakn view bangunan edukatif-komersial yang menuntut ekspose bangunan yang optimal. View yang optimal ialah berorientasi ke Barat dimana view bangunan menghadap langsung ke jalan raya.

Penerangan alami dalam ruang dengan mengoptimalkan sinar matahari. Yaitu pada ruang tidur/kamar, dapur/ruang makan, fasilitas kantor, perpustakaan dan ruang latihan fisik.

Untuk mengurangi panas dalam bangunan dikarenakan bangunan tepat berada pada arah gerak matahari yaitu pada bagian barat dan timur gedung maka didesain dengan peletakan vegetasi pada kedua bagian tersebut untuk mengurangi sinar matahari berlebih.

Untuk meminimalisir kabisingan yang ada pada kawasan Olahraga terpau ini maka diperlukan meletakkan vegetasi disekitar tapak yang langsung berhubugan dengan sumber bising, diharapkan dapat memfilter suara bising dari jalan raya.

\section{DAFTAR PUSTAKA}

- Ching, Francis D.K. Architecture : "Form, Space And Order”; Van Nostrand Reinhold Company. New York; 1996.

- Trancik, Roger; "Finding Lost Space, Theories of Urban Design" ; Van Nostrand Reinhold Company; 1986

- KONI Provinsi Sulawesi Selatan, 2011-2014)

- Neufert, Ernst. 1996.Data Arsitek Jild 1 Edisi 33. Erlangga. Jakarta.

- Orientasi matahari pada tapak (Sumber : Badan perencana pembangunan daearah, 2015). 